Article

\title{
Forecasting Clean Energy Consumption in China by 2025: Using Improved Grey Model GM (1, N)
}

\author{
Maolin Cheng ${ }^{1, *}$, Jiano Li ${ }^{1}$, Yun Liu ${ }^{1}$ and Bin Liu ${ }^{2}$ \\ 1 Department of Statistics, Suzhou University of Science and Technology, Suzhou 215009, China; \\ 1911082001@post.usts.edu.cn (J.L.); liuyun_1133@163.com (Y.L.) \\ 2 Department of Finance, Suzhou University of Science and Technology, Suzhou 215009, China; \\ ustsliubin@yeah.net \\ * Correspondence: cml@mail.usts.edu.cn
}

Received: 21 December 2019; Accepted: 16 January 2020; Published: 18 January 2020

check for updates

\begin{abstract}
Forecasting China's clean energy consumption has great significance for China in making sustainably economic development strategies. Because the main factors affecting China's clean energy consumption are economic scale and population size, and there are three variables in total, this paper tries to simulate and forecast China's clean energy consumption using the grey model GM $(1,3)$. However, the conventional grey GM $(1, N)$ model has great simulation and forecasting errors, the main reason for which is the structural inconsistency between the grey differential equation for parameter estimation and the whitening equation for forecasting. In this case, this paper improves the conventional model and provides an improved model GM $(1, N)$. The modeling results show that the improved grey model GM $(1, \mathrm{~N})$ built with the method proposed improves simulation and forecasting precision greatly compared with conventional models. To compare the model with other forecasting models, this paper builds a grey GM $(1,1)$ model, a regression model and a difference equation model. The comparison results show that the improved grey model GM $(1, N)$ built with the method proposed shows simulation and forecasting precision superior to that of other models as a whole. In the final section, the paper forecasts China's clean energy consumption from 2019 to 2025 using the improved grey model GM $(1, N)$. The forecasting results show that, by 2025, China's clean energy consumption shall reach the equivalent of 1.504976082 billion tons of standard coal. From 2019 to 2025, clean energy consumption shall increase by $11.32 \%$ annually on average, far above the economic growth rate, indicating China's economic growth shall have a great demand for clean energy in the future. Studies have shown that China's clean energy consumption shall increase rapidly with economic growth and population increase in the next few years.
\end{abstract}

Keywords: clean energy consumption; grey model; time response equation; forecasting precision

\section{Introduction}

The Chinese economy is in an important development stage- the middle and late period of urbanization. Currently, economic growth has entered into the new normal, and environmental management also faces great challenges. China is currently the biggest $\mathrm{CO}_{2}$ and $\mathrm{SO}_{2}$ emitting country in the world. The emission of $\mathrm{SO}_{2}$ causes the deaths of approximately 0.18 million people each year in China and has a medical cost of more than CNY 0.3 trillion. The latest statistics from the World Bank show that China's total economic loss caused by air and water pollution accounts for about $8-12 \%$ of China's GDP. Because of the great damages to the environment made by extensive economic growth, China has to find a sustainable development mode for the mutual benefit of economic growth and environmental protection. In the urbanization stage, the main reasons for the continuously increasing environmental load in China include the rapid increase in energy consumption brought 
by the improvement of the urbanization level and the energy consumption structure dominated by fossil energy emitting high pollutants. For this reason, to reduce the large number of emission of air pollutants, such as $\mathrm{CO}_{2}$ and $\mathrm{SO}_{2}$, in the process of urbanization, and break through the bottleneck of sustainable economic growth caused by environmental pollution, China vigorously advocates the energy conservation of all the people and accelerates the development of clean and renewable energy to replace fossil energy. Apparently, environmental management is the core task currently for China to promote sustainable economic development and increasing the proportion of clean energy consumption has become the key content in China's environmental management strategies. Forecasting clean energy consumption has great significance for China in making sustainably economic development strategies.

China's clean energy studied in the paper includes renewable energy, such as ocean energy, solar energy, wind energy, biological energy, hydraulic energy, geothermal energy, hydrogen energy, and so on, and nonrenewable energy, such as nuclear energy, and so on. China generally converts all energy statistics into the equivalents of tons of standard coal.

China's energy production and consumption has realized the leaping development over the 70 years since its establishment, and China's energy structure is changing from the raw-coal-dominated type to the clean \& low-carbon type. With the research and development of technology and the fast changes in equipment manufacturing capacity, China's clean energy shall have a continuously rising right of speech in the international market. China's installed capacity for clean energy has increased by more than 1000 times and its power generating capacity has increased by over 2000 times over the past 70 years. In 1949, the only installed unit of power of clean energy in China was the hydropower installed unit. However, by 2018, China's installed capacity of hydropower, wind power and photovoltaics has been 352,260 MW, 184,260 MW and 174,630 MW, respectively, all ranked first in the world. In China, the total proportion of clean energy in total energy consumption was about $22.2 \%$ in 2018 , increasing by $7.7 \%$ compared with the figure in 2012; however, to realize the goals of $25 \%$ and $35 \%$ in 2020 and 2030, China needs to do a lot more. The future variation trend of clean energy consumption in China is of common concern, and so forecasting China's clean energy consumption has great significance for China to make energy development strategies.

Many researchers have performed studies on forecasting clean energy consumption at home and abroad. Qian et al. [1] proposed various methods for improving the forecast precision of wind power generation. They mixed different technologies to construct hybrid models. Their research first decomposed the wind speed/rate time sequence into relatively stable subsequences and then built forecasting models for each subsequence. Decomposition-based hybrid forecasting models were classified into different groups based on the decomposition methods. They explored decomposition methods in the background of optional forecasting algorithms. Lu [2] offered a renewable energy forecasting method with small samples. The research combined the heuristic fuzzy time sequence with the improved grey forecasting model to improve forecasting precision. In particular, this proposed method could improve the forecasting precision of renewable energy to more than $90 \%$, so its forecasting results could be used by managers for reference when making energy strategies. Tsai et al. [3] studied the forecasting of growth trends of renewable energy consumption in China. Their research only collected 22 samples because renewable energy was an emerging technology. The amount of historical data samples of renewable energy was limited, and the data did not follow the normal distribution; in this case, the forecasting methods analyzing a great amount of data were not applicable, so researchers adopted a grey forecasting method. This method could be used to make comprehensive analyses, observe the system's development and changes and make long-term forecasts. However, to overcome the limitations of studies on grey forecasting and improve forecasting precision, this research adopted the grey model GM $(1,1)$ and the nonlinear grey Bernoulli model $\operatorname{NGBM}(1,1)$ for theoretical derivation and verification, and then compared the two models with the regression analysis model to determine the models' forecasting precision and fitness. In terms of mean absolute error, mean square error and mean absolute percentage error, the $\operatorname{NGBM}(1,1)$ had the highest forecasting precision, followed by the GM $(1,1)$ and the regression analysis model. The results show 
the improved NGBM $(1,1)$ grey forecasting model had a good forecasting ability. Abedinia et al. [4] proposed a hybrid forecasting method based on the neural network and the metaheuristic algorithm for solar energy forecasting. They optimized the free parameters of the neural network using the metaheuristic algorithm. The method included a two-level characteristic selective filter for invalid input characteristics. To verify the effectiveness of the forecasting method proposed, they used the method in a practical engineering test case. The test results show that the method had a certain superiority compared with other forecasting methods. Reikard et al. [5] forecasted wave energy in a short time. They made simulations in three places-Canada, Britain and British Columbia-and calculated the power series of six types of wave energy converter (WECs), of which four types were for deepwater and two types were for shallow water. They made forecasts using the physics-based model and the statistical model. Considering the inherent nonlinearity and randomness of wind energy forecasting, Yang et al. [6] developed a hybrid wind energy forecasting and analysis system containing the deterministic forecasting module and the uncertainty analysis module to alleviate the challenges in current research. The developed hybrid system included three steps: first, preprocessing data, capturing and digging the wind energy time sequence's main characteristics, and reducing the negative influence of noise; second, proposing a multi-objective optimization method, realizing the forecasting of subsequences and improving the precision and stability of forecasting precision; finally, searching for the optimal function using the optimized extreme learning machine based on various modeling objectives, and getting the deterministic forecasting and uncertainty analysis results. The researchers made an experimental simulation using the data measured in three wind power plants in an actual wind power plant. The results show that the system developed had good performance in engineering applications. The system was not only an effective tool for wind energy's deterministic forecasting and uncertainty analysis but also could be used in the engineering application filed in the future. Xiao et al. [7] summarized the hybrid models of wind energy forecasting and classified the hybrid forecasting methods of wind energy. To further research hybrid models, they proposed two hybrid models, the hybrid models of NNCT (Non-Negative Constraint Theory) and artificial intelligent algorithm. Using the regional data of Chengde, China, they verified the effectiveness of hybrid models and the results show that the hybrid models proposed offered satisfactory forecasting results compared with existing conventional hybrid models. Rodriguez et al. [8] proposed the ANN, an artificial neural network forecasting photovoltaic generating units' solar energy generating capacity. The tool developed by them solved the problem of complexity of system control based on solar energy. The tool could forecast related parameters of solar energy generation, so that people could estimate the future power generation and then optimize the power grid. The tool used an artificial neural network developed with MATLAB software. The results show that the difference between energy generated actually and forecasted was about $0.5-9 \%$, indicating the accuracy was sufficient to be installed in the system of integrated solar power generators. Kim and Hur [9] proposed a method for short-term probability forecasting of wind energy through enhanced integration. The improved integrated forecasting methods were mainly divided into time integrated forecasting and space integrated forecasting. The researchers used the auto-regression integrated mobile averaging method, the polynomial regression method of time sequence data, and the analog integrated method of probability for the time integrated forecasting. The space integrated forecasting was realized through the geographical statistic model and the geographical attribute data interpolation. In addition, they used the stochastic simulation integrated method to reduce the uncertainty of wind power forecasting and considered adopting the numerical weather forecasting model for accurate wind power forecasting. The experiment results show that the model showed good performance while offering probability forecasting. Zheng et al. [10] made a numerical forecasting experiment for China's wave energy using the latest wave model and built a short-term wave energy forecasting system suitable for China's seas. Considering the wave power density (WPD), the wave energy rise, the diurnal total energy storage and the effective energy storage, the researchers designed a series of short-term wave energy forecasting products. Because China's seas and the surrounding waters have relatively frequent cold air in winter, 
early spring and late autumn, there is sufficient wave energy. Although wind energy and solar energy has been the main source of renewable energy by far, wave energy is increasingly being considered as a feasible energy source in coastal areas. Reikard et al. [11] combined wind energy with solar energy in the research and integrated the wave energy into the power grid. The northwest Pacific Ocean area in America has a good combination of the three types of energy. Solar power generation is characterized by a daily cycle and seasonality, but also shows nonlinear changes due to clouds, atmospheric turbidity and rainfall. Wind power generation is mainly controlled by the large slope incident, i.e., the irregular transition between high power state and low power state. Wave energy shows seasonal cycles and is stable generally. Researchers made a forecasting test of three types of renewable energy for $1-4 \mathrm{~h}$ and found that wave energy could be forecasted more easily than wind energy and solar energy. Simulation results showed that wave energy had a forecasting error of $5-7 \%$ in one hour, while solar energy and wind energy had the errors of $17 \%$ and $22 \%$, respectively. Wave energy had the lowest storage cost, which was less than a half of the cost of wind energy or solar energy. Galván et al. [12] gave an interval forecasting method for renewable energy (solar energy). They proposed a multi-objective evolution method which could optimize two objectives at the same time. The method built a complicated nonlinear model using a neural network, of which the output is the top and bottom limitations of the forecasting interval. They compared the results with the results of the single object optimization with a similar neural network structure and the baseline algorithm and found that the neural network could offer accurate results. Li et al. [13] proposed a hybrid forecasting method for intelligent residential districts' net load forecasting specific for the short-term forecasting of intelligent residential districts' wind power and photovoltaic power generation and load. The method could build a real-time forecasting model with self-adjusting parameters. Compared with conventional forecasting methods, such as the SVM (Support Vector Machine), the method could make a fluctuation optimization to the forecasting model's parameters. In addition, to reduce the calculation time in the forecasting process, the researchers proposed an optimized grid genetic algorithm. Therefore, the method could improve forecasting precision even if there was great uncertainty in wind power and photovoltaic power generation and load. They made a comparative analysis on conventional forecasting methods and the forecasting method proposed through a detailed case analysis. The analysis results show that the method proposed had an adaptive ability for the fluctuations of wind power and photovoltaic power generation, and improved forecasting precision and efficiency greatly. Li et al. [14] estimated and compared two comment methods, the ANN and the SVR (support vector regression), for the purpose of forecasting the energy output of solar photovoltaic systems in Florida. Basing on the machine learning algorithm tested, they proposed a delaminating method which determined the model's precision by calculating error statistics, such as the MBE (Mean Biased Error), the MAE (Mean Absolute Error), the RMSE (Root Mean Square Error), the MPE (Mean Percentage Error) and the rRMSE (relative RMSE). Jeon et al. [15] developed short-term forecasting for waves. Wave energy's discontinuity stimulated the applications of probability forecasting. The researchers made probability forecasting of wave energy with the unconditional kernel density estimation, the conditional kernel density estimation, the univariate and bivariate ARMA-GARCH (Auto-Regressive Moving Average-Generalized Auto-Regressive Conditional Heteroscedasticity) model and the regression-based method. They built a binary ARMA-GARCH model. The empirical study proved that the binary ARMA-GARCH model of fluctuation height and period had the highest forecasting precision for wave energy as a whole. Ibarra-Berastegi et al. [16] analyzed the performance of three statistical models and proposed a famous physics-based wave energy flux forecasting model. The forecasts were of five buoys in the Bay of Biscay within $24 \mathrm{~h}$. The data resolution was once per hour. The time framework of 1999 2005 was used for training models. The forecasted time was within 6 years, from 2006 to 2012. The statistical forecasting models used three technologies: the analogy, the random forest and the combination of two methods. The physical model was a wave model (WAM). The forecasting results show that the random forest model was superior to other models. The random forest model had a high-precision forecasting ability because it could combine the information offered by atmospheric and sea state 
variables successfully. Merigaud et al. [17] explored the full range of wave modeling activity, including various time scales, and introduced modeling methods of the time scales and the causality input driving the models. Some models were based on the physical description of the system, including sounding, while some models only used measured data to form time sequence models. Their research introduced the proper structures of forecasting models and how to make parameter estimations for models in details, and offered some cases to explain these modeling methods. Ma et al. [18] proposed and used a machine learning forecasting algorithm, which did not contain a great number of independent variables or hypotheses, for the modeling and forecasting of American renewable energy consumption (REC). They forecasted the biomass and hydro power's REC in years 2009-2016. Martín-Vázquez et al. [19] forecasted wind power generation capacity using two machine learning methods. The individual method constructed a model for each layer, while the global method obtained a model allied to all layers. Each method had its advantages and disadvantages. The SVM was used to construct the individual and global models. The research performed tests with the energy production data obtained from wind power plants and the meteorological data offered by the European Center for Medium-Range Weather Forecasting. Additionally, considering the great number of variables involved, to improve the models' performance, the researchers adopted a characteristics selection algorithm. The experiment results show that the global model was more accurate than the single model, especially in the case of characteristic selection. Mehedintu et al. [20] analyzed the trend of renewable energy consumption using the data of 28 countries of the EU. The data came from the Eurostat's database of the years 1995-2016. The researchers got the simple statistics of three macroeconomic indexes on the level of the EU and made an economic analysis, and then estimated the evolution of renewable energy consumption's proportion in the final energy consumption using five regression models (the polynomial, ARIMA). The empirical estimation of the proportion of renewable energy in the final energy consumption showed that all groups had a growth trend. Dumitru and Gligor [21] analyzed different time sequence modeling methods for the purpose of forecasting the power output of renewable energy like wind energy. They used two models, the random model (ARIMA) and the model based on neural network (FFANN or MLP) for the forecasting.

In various forecasting models, the grey model is an important type. In the applications of grey model, many researchers used the GM $(1,1)$ model and its improved models for forecasting. Because clean energy consumption is affected by other variables, it's proper to build a grey model GM $(1, \mathrm{~N})$ for the forecasting of clean energy consumption. In recent years, the GM $(1, N)$ model has been used widely [22-26]. However, when forecasting with the models in practice, there are always great errors, for which reason many researchers have studied the model. Currently the studies focus on the model's optimization, modification and extension. Zhengxin Wang [27] proposed a grey multivariable time-lag GM $(1, N)$ model and its solving method for the modeling of small-sample systems with time-lag causality. Haijun Su and Yi Shao [28] proposed an optimized combination GM $(1, \mathrm{~N})$ model considering the model's defects in simulation and forecasting. Ji Huang [29] proposed a grey multivariable delay GM $(1, N)$ model for the control system with little information, many variables and lagged input and output, gave the model's parameter estimation form and approximation time response formula and obtained two derived models. Gaofeng Zhang et al. [30] made an experimental study on the grey multivariable self-memory model and gave the method building grey GM $(1, \mathrm{~N})$ self-memory models. Manxi He and Qin Wang [31] made a modeling mechanism analysis on a grey differential equation GM $(1, N)$ according to the time sequence's structure and characteristics, and proposed a new algorithm to build GM $(1, \mathrm{~N})$ forecasting models based on the Simpson formula. Song Ding et al. [32] introduced a dummy variable into the conventional GM $(1, \mathrm{~N})$ model to construct a GM $(1, \mathrm{~N})$ model controlled by a dummy variable. Wei Zhou and Zhigeng Fang [33] proposed two nonlinear optimization GM (1, N) models. Qiuping Wang et al. [34] combined the grey theory with the Markov model for forecasting to improve forecasting precision. Xiaojun Bi and Xin'an Wu [35] offered a multistage grey model GM $(1, N)$ with a feedback mechanism for complex systems. These research methods improved GM $(1, \mathrm{~N})$ model's forecasting precision to different extents. In fact, a main reason for the poor forecasting precision of 
conventional GM $(1, N)$ model is the structural inconsistency between the grey differential equation for parameter estimation and the whitening equation for forecasting [36-38]. The paper derives the modified model of conventional grey differential equation on the basis of the whitening equation, in which way the structure of the grey differential equation obtained is basically consistent with the structure of the whitening equation, and then substitutes the parameter estimate obtained with the grey differential equation into the whitening equation (time response equation), and the solution obtained shows small forecasting errors. In the grey differential equation, the selection of background value is very important. Generally, the background value is the adjacent mean sequence, i.e., the generating coefficient of background value is an equal-weighted constant, which is the approximate value of the background value, but sometimes the model forecasting precision is poor, so many scholars have made important studies on this problem [39-43]. However, in fact, the background value function has many forms. If the generating coefficient of the background value is an unequal-weighted constant or unequal-weighted variable, to improve forecasting precision, we can use an optimization method to select the generating coefficient. This paper uses the grey differential equation of an improved GM $(1, N)$ model for parameter estimation and gives a parameter estimation method with optimized background value. For the time response equation of conventional GM $(1, N)$ model, there is generally no analytical solution, and researchers generally use an approximation method [44-48]. This paper gives a scientific solving method for the time response equation of the improved model. The empirical analysis shows that the improved grey model GM $(1, N)$ proposed and the method proposed improve simulation and forecasting precision greatly compared with conventional models. To compare with other models in terms of forecasting, this paper builds a grey GM $(1,1)$ model, a regression model and a difference equation model. The comparison results show that the improved grey model GM $(1, N)$ built with the method proposed is superior to other models as a whole in terms of simulation and forecasting precision. In the final part, this paper forecasts China's clean energy consumption using the improved model and method proposed. Forecasting results show that China's clean energy consumption shall grow rapidly with the growth of economy and population in the next few years.

\section{Methodology}

\subsection{Conventional Grey Model GM $(1, N)$}

We supposed the system characteristic factor's time sequence to be $\left\{x_{1}^{(0)}(k)\right\}$ and correlative factor's time sequence to be $\left\{x_{i}^{(0)}(k)\right\}(i=2,3, \cdots, p)$, i.e., $x_{i}^{(0)}(k)=\left\{x_{i}^{(0)}(1), x_{i}^{(0)}(2), \cdots, x_{i}^{(0)}(N)\right\}$ $(i=1,2, \cdots, N)$.

The first-order accumulated generating equation is

$$
x_{i}^{(1)}(k)=\sum_{i=1}^{k} x_{i}^{(0)}(i), k=1,2, \cdots, N
$$

The conventional grey model GM $(1, \mathrm{~N})$ 's grey differential equation is

$$
x_{1}^{(0)}(k)+a_{1} z_{1}^{(1)}(k)=b_{2} x_{2}^{(1)}(k)+b_{3} x_{3}^{(1)}(k)+\cdots+b_{p} x_{p}^{(1)}(k)
$$

in which the background value $z_{1}^{(1)}(k)=0.5 x_{2}^{(1)}(k-1)+0.5 x_{2}^{(1)}(k)$.

The whitening equation is

$$
\frac{d x_{1}^{(1)}(t)}{d t}+a_{1} x_{1}^{(1)}(k)=b_{2} x_{2}^{(1)}(k)+b_{3} x_{3}^{(1)}(k)+\cdots+b_{p} x_{p}^{(1)}(k)
$$


Its solution is

$$
x_{1}^{(1)}(t)=e^{-a t}\left(x_{1}^{(1)}(1)-t \sum_{i=2}^{p} b_{i} x_{i}^{(1)}(1)+\sum_{i=2}^{p} \int b_{i} x_{i}^{(1)}(t) e^{a t} d t\right)
$$

The equation above generally has no analytical expression. When time sequence $\left\{x_{i}^{(1)}(k)\right\}$ $(i=2,3, \cdots, p)$ had few changes in time interval $\left[t_{k}, t_{k+1}\right]$, the time response equation of $\mathrm{GM}(1, \mathrm{~N})^{\prime} \mathrm{s}$ whitening equation was approximate to

$$
x_{1}^{(1)}(t+1)=e^{-a t}\left(x_{1}^{(1)}(1)-\frac{1}{a} \sum_{i=2}^{p} b_{i} x_{i}^{(1)}(t+1)\right)+\frac{1}{a} \sum_{i=2}^{p} b_{i} x_{i}^{(1)}(t+1)
$$

where

$$
\begin{gathered}
\hat{B}=\left[\begin{array}{c}
a \\
b_{2} \\
b_{3} \\
\cdots \\
b_{p}
\end{array}\right]=\left(X^{\prime} X\right)^{-1} X^{\prime} Y \\
X=\left[\begin{array}{cccc}
-0.5\left(x^{(1)}(2)+x^{(1)}(1)\right) & x_{2}^{(1)}(2) & \cdots & x_{p}^{(1)}(2) \\
-0.5\left(x^{(1)}(3)+x^{(1)}(2)\right) & x_{2}^{(1)}(3) & \cdots & x_{p}^{(1)}(3) \\
\cdots & \cdots & & \cdots \\
-0.5\left(x^{(1)}(N)+x^{(1)}(N-1)\right) & x_{2}^{(1)}(N) & \cdots & x_{p}^{(1)}(N)
\end{array}\right], Y=\left[\begin{array}{l}
x^{(0)}(2) \\
x^{(0)}(3) \\
\cdots \\
x^{(0)}(N)
\end{array}\right]
\end{gathered}
$$

Then, from $\hat{x}^{(0)}(t)=\hat{x}^{(1)}(t)-\hat{x}^{(1)}(t-1)$, we calculated the simulated value and forecasted value of original sequence.

If time sequence $\left\{x_{i}^{(1)}(k)\right\}(i=2,3, \cdots, p)$ had great changes in time interval $\left[t_{k}, t_{k+1}\right]$, we could substitute the time response function of GM $(1,1)$ model built with them into $\left\{x_{i}^{(1)}(t)\right\}(i=2,3, \cdots, p)$ of $x_{1}^{(1)}(t)=e^{-a t}\left(x_{1}^{(1)}(1)-t \sum_{i=2}^{p} b_{i} x_{i}^{(1)}(1)+\sum_{i=2}^{p} \int b_{i} x_{i}^{(1)}(t) e^{a t} d t\right)$ to get the analytical expression of time response equation of GM $(1, \mathrm{~N})$ model.

\subsection{Improved Grey Model GM $(1, N)$}

\subsubsection{Mechanism Analysis on Improved Grey Model GM (1, N)}

We supposed the system characteristics factor's time sequence to be $\left\{x_{1}^{(0)}(k)\right\}$ and correlative factor's time sequence to be $\left\{x_{i}^{(0)}(k)\right\}(i=2,3, \cdots, p)$, i.e., $x_{i}^{(0)}(k)=\left\{x_{i}^{(0)}(1), x_{i}^{(0)}(2), \cdots, x_{i}^{(0)}(N)\right\}$ $(i=1,2, \cdots, N)$.

The first-order accumulated generating equation is

$$
x_{i}^{(1)}(k)=\sum_{i=1}^{k} x_{i}^{(0)}(i), k=1,2, \cdots, N
$$

To improve grey model GM $(1, N)$ 's forecasting precision, we modified the conventional whitening equation to be

$$
\frac{d x_{1}^{(1)}(t)}{d t}+a_{1} x_{1}^{(1)}(k)=b_{2} x_{2}^{(1)}(t)+b_{3} x_{3}^{(1)}(t)+\cdots+b_{p} x_{p}^{(1)}(t)+b
$$


We used the Lagrange's mean value theorem to derivable curve $x_{1}^{(1)}(t)$ in $(k-1, k)$, and there was a $\xi_{k} \in(k-1, k)$, allowing

$$
x_{1}^{(1)}(k)-x_{1}^{(1)}(k-1)=\left.\frac{d x_{1}^{(1)}}{d t}\right|_{t=\xi_{k}}
$$

i.e., $x_{1}^{(0)}(k)=\left.\frac{d x_{1}^{(1)}}{d t}\right|_{t=\xi_{k}}$.

In this case, we made $t=\xi_{k}$ for both sides of $\frac{d x_{1}^{(1)}(t)}{d t}+a_{1} x_{1}^{(1)}=b_{2} x_{2}^{(1)}(t)+b_{3} x_{3}^{(1)}(t)+\cdots+$ $b_{p} x_{p}^{(1)}(t)+b$, and then got

$$
x_{1}^{(0)}(k)+a_{1} x_{1}^{(1)}\left(\xi_{k}\right)=b_{2} x_{2}^{(1)}\left(\xi_{k}\right)+b_{3} x_{3}^{(1)}\left(\xi_{k}\right)+\cdots+b_{p} x_{p}^{(1)}\left(\xi_{k}\right)+b
$$

where $x_{i}^{(1)}\left(\xi_{k}\right)(i=1,2, \cdots, p)$ is the background value. We reecorded $z_{i}^{(1)}(k)=x_{i}^{(1)}\left(\xi_{k}\right)$, and then got the modified grey differential equation

$$
x_{1}^{(0)}(k)+a_{1} z_{1}^{(1)}(k)=b_{2} z_{2}^{(1)}(k)+b_{3} z_{3}^{(1)}(k)+\cdots+b_{p} z_{p}^{(1)}(k)+b
$$

Generally, $x_{i}^{(1)}(t)$ was a monotonic sequence, and then $x_{i}^{(1)}\left(\xi_{k}\right) \in\left(x_{i}^{(1)}(k-1), x_{i}^{(1)}(k)\right)$, and there was

$$
x_{i}^{(1)}\left(\xi_{k}\right)=\alpha_{k} x_{i}^{(1)}(k-1)+\left(1-\alpha_{k}\right) x_{i}^{(1)}(k),\left(0 \leq \alpha_{k} \leq 1\right)
$$

i.e., $z_{i}^{(1)}(k)=\alpha_{k} x_{i}^{(1)}(k-1)+\left(1-\alpha_{k}\right) x_{i}^{(1)}(k),(i=1,2, \cdots, p)$.

\subsubsection{Time Response Equation of Improved Grey Model GM $(1, \mathrm{~N})$}

To get the solution of grey model GM $(1, N)$ 's whitening equation, we substituted the time response equation for $x_{i}^{(1)}(i=2,3, \cdots, p)$ in the whitening equation, and so supposed

$$
x_{i}^{(1)}(t)=\left(x_{i}^{(1)}(1)-\frac{c_{i}}{a_{i}}\right) e^{-a_{i}(t-1)}+\frac{c_{i}}{a_{i}},(i=2,3, \cdots, p)
$$

and then the whitening equation was

$$
\frac{d x_{1}^{(1)}(t)}{d t}+a_{1} x_{1}^{(1)}=\sum_{i=2}^{p} b_{i}\left[\left(x_{i}^{(1)}(1)-\frac{c_{i}}{a_{i}}\right) e^{-a_{i}(t-1)}+\frac{c_{i}}{a_{i}}\right]+b
$$

i.e.,

$$
\frac{d x_{1}^{(1)}(t)}{d t}+a_{1} x_{1}^{(1)}=\sum_{i=2}^{p}\left[b_{i} e^{a_{i}}\left(x_{i}^{(1)}(1)-\frac{c_{i}}{a_{i}}\right) e^{-a_{i} t}+\frac{b_{i} c_{i}}{a_{i}}\right]+b
$$

We recorded $B_{i}=b_{i} e^{a_{i}}\left(x_{i}^{(1)}(1)-\frac{c_{i}}{a_{i}}\right)$ and $B_{0}=\sum_{i=2}^{p}\left(\frac{b_{i} c_{i}}{a_{i}}\right)+b$, and then

$$
\frac{d x_{1}^{(1)}(t)}{d t}+a_{1} x_{1}^{(1)}(t)=\sum_{i=2}^{p} B_{i} e^{-a_{i} t}+B_{0}
$$


The solution of $\frac{d x_{1}^{(1)}(t)}{d t}+a_{1} x_{1}^{(1)}(t)=B_{i} e^{-a_{i} t}$ was

$$
\begin{aligned}
x_{1}^{(1)}(t) & =e^{\int_{t_{0}}^{t}-a_{1} d \xi} \cdot\left[x^{(1)}(1)+\int_{t_{0}}^{t} e^{\int_{t_{0}}^{\eta} a_{1} d \xi} B_{i} e^{-a_{i} t} d \eta\right] \\
& =e^{-a_{1}\left(t-t_{0}\right)}\left[x^{(1)}(1)+\int_{t_{0}}^{t} e^{a_{1}\left(\eta-t_{0}\right)} B_{i} e^{-a_{i} t} d \eta\right] \\
& =e^{-a_{1}\left(t-t_{0}\right)}\left[x^{(1)}(1)+\left.\left(\frac{B_{i}}{-a_{i}+a_{1}} \cdot e^{\left(-a_{i}+a_{1}\right) \eta-a_{1} t_{0}}\right)\right|_{t_{0}} ^{t}\right] \\
& =e^{a_{1} t_{0}}\left(x^{(1)}(1)-\frac{B_{i}}{-a_{i}+a_{1}} e^{-a_{i} t_{0}}\right) e^{-a_{1} t}+\frac{B_{i}}{-a_{i}+a_{1}} e^{-a_{i} t}
\end{aligned}
$$

In this case, the solution of $\frac{d x_{1}^{(1)}(t)}{d t}+a_{1} x_{1}^{(1)}(t)=\sum_{i=2}^{p} B_{i} e^{-a_{i} t}+B_{0}$ was

$$
\begin{aligned}
& x_{1}^{(1)}(t)=\sum_{i=2}^{p}\left[e^{a_{1} t_{0}}\left(x^{(1)}(1)-\frac{B_{i}}{a_{1}-a_{i}} e^{-a_{i} t_{0}}\right) e^{-a_{1} t}+\frac{B_{i}}{a_{1}-a_{i}} e^{-a_{i} t}\right] \\
& +e^{a_{1} t_{0}}\left(x^{(1)}(1)-\frac{B_{0}}{a_{1}}\right) e^{-a_{1} t}+\frac{B_{0}}{a_{1}}
\end{aligned}
$$

i.e., the time response function of whitening equation was

$$
\begin{aligned}
& x_{1}^{(1)}(t)=\sum_{i=2}^{p}\left[e^{a_{1}}\left(x^{(1)}(1)-\frac{b_{i} e^{a_{i}}\left(x_{i}^{(1)}(1)-\frac{c_{i}}{a_{i}}\right)}{a_{1}-a_{i}} e^{-a_{i}}\right) e^{-a_{1} t}+\frac{b_{i} e^{a_{i}\left(x_{i}^{(1)}(1)-\frac{c_{i}}{a_{i}}\right)}}{a_{1}-a_{i}} e^{-a_{i} t}\right] \\
& +e^{a_{1} t_{0}}\left(x^{(1)}(1)-\frac{\sum_{i=2}^{p}\left(\frac{b_{i} c_{i}}{a_{i}}\right)+b}{a_{1}}\right) e^{-a_{1} t}+\frac{\sum_{i=2}^{p}\left(\frac{b_{i} c_{i}}{a_{i}}\right)+b}{a_{1}}
\end{aligned}
$$

\subsubsection{Parameter Estimation of Improved Grey Model GM (1, N)}

The improved grey differential equation is

$$
x_{1}^{(0)}(k)+a_{1} z_{1}^{(1)}(k)=b_{2} z_{2}^{(1)}(k)+b_{3} z_{3}^{(1)}(k)+\cdots+b_{p} z_{p}^{(1)}(k)+b
$$

where $z_{i}^{(1)}(k)=\alpha_{k} x_{i}^{(1)}(k-1)+\left(1-\alpha_{k}\right) x_{i}^{(1)}(k)$.

If the generating coefficient was an equal-weighted weight, i.e., $\alpha_{k}=0.5$, the estimate of parameter was

$$
\hat{B}=\left[\begin{array}{c}
a_{1} \\
b_{2} \\
b_{3} \\
\cdots \\
b_{p} \\
b
\end{array}\right]=\left(X^{\prime} X\right)^{-1} X^{\prime} Y
$$

where

$$
\begin{gathered}
X=\left[\begin{array}{ccccc}
-0.5\left(x_{1}^{(1)}(2)+x_{1}^{(1)}(1)\right) & 0.5\left(x_{2}^{(1)}(2)+x_{2}^{(1)}(1)\right) & \cdots & 0.5\left(x_{p}^{(1)}(2)+x_{p}^{(1)}(1)\right) & 1 \\
-0.5\left(x_{1}^{(1)}(3)+x_{1}^{(1)}(2)\right) & 0.5\left(x_{2}^{(1)}(3)+x_{2}^{(1)}(2)\right) & \cdots & 0.5\left(x_{p}^{(1)}(3)+x_{p}^{(1)}(2)\right) & 1 \\
\cdots & \cdots & \cdots & \cdots & \cdots \\
-0.5\left(x_{1}^{(1)}(N)+x_{1}^{(1)}(N-1)\right) & 0.5\left(x_{2}^{(1)}(N)+x_{2}^{(1)}(N-1)\right) & \cdots & 0.5\left(x_{p}^{(1)}(N)+x_{p}^{(1)}(N-1)\right) & 1
\end{array}\right] \\
Y=\left[\begin{array}{l}
x^{(0)}(2) \\
x^{(0)}(3) \\
\cdots \\
x^{(0)}(N)
\end{array}\right]
\end{gathered}
$$


If the generating coefficient is an unequal-weighted constant, i.e., $\alpha_{k}=\alpha$, in which case,

$$
z_{i}^{(1)}(k)=\alpha x_{i}^{(1)}(k-1)+(1-\alpha) x_{i}^{(1)}(k) \quad(0 \leq \alpha \leq 1)
$$

The estimate of the parameter is

$$
\hat{B}=\left[\begin{array}{c}
a_{1} \\
b_{2} \\
b_{3} \\
\cdots \\
b_{p} \\
b
\end{array}\right]=\left(X^{\prime} X\right)^{-1} X^{\prime} Y
$$

where

$$
\begin{gathered}
X=\left[\begin{array}{ccccc}
-\alpha x_{1}^{(1)}(1)-(1-\alpha) x_{1}^{(1)}(2) & \alpha x_{2}^{(1)}(1)+(1-\alpha) x_{2}^{(1)}(2) & \cdots & \alpha x_{p}^{(1)}(1)+(1-\alpha) x_{p}^{(1)}(2) & 1 \\
-\alpha x_{1}^{(1)}(2)-(1-\alpha) x_{1}^{(1)}(3) & \alpha x_{2}^{(1)}(2)+(1-\alpha) x_{2}^{(1)}(3) & \cdots & \alpha x_{p}^{(1)}(2)+(1-\alpha) x_{p}^{(1)}(3) & 1 \\
\cdots & \cdots & \cdots & \cdots & \cdots \\
-\alpha x_{1}^{(1)}(N-1)-(1-\alpha) x_{1}^{(1)}(N) & \alpha x_{2}^{(1)}(N-1)+(1-\alpha) x_{2}^{(1)}(N) & \cdots & \alpha x_{p}^{(1)}(N-1)+(1-\alpha) x_{p}^{(1)}(N) & 1
\end{array}\right] \\
Y=\left[\begin{array}{l}
x^{(0)}(2) \\
x^{(0)}(3) \\
\cdots \\
x^{(0)}(N)
\end{array}\right]
\end{gathered}
$$

We used the optimization method to define $\alpha$. That is, in $[0,1]$, we took the value of $\alpha$ from 0 to 1 by the step size of 0.01 , and chose the $\alpha$, making MAPE $=\frac{1}{N-1} \sum_{t=2}^{N}\left|\frac{x_{1}^{(0)}(t)-\hat{x}_{1}^{(0)}(t)}{x_{1}^{(0)}(t)}\right| \times 100 \%$ the minimum.

After getting all the parameters, we substituted the parameters into the following time sequence response equation:

$$
\begin{aligned}
& x_{1}^{(1)}(k)=\sum_{i=2}^{p}\left[e^{a_{1}}\left(x^{(1)}(1)-\frac{b_{i} e^{a_{i}}\left(x_{i}^{(1)}(1)-\frac{c_{i}}{a_{i}}\right)}{a_{1}-a_{i}} e^{-a_{i}}\right) e^{-a_{1} k}+\frac{b_{i} e^{a_{i}}\left(x_{i}^{(1)}(1)-\frac{c_{i}}{a_{i}}\right)}{a_{1}-a_{i}} e^{-a_{i} k}\right] \\
& +e^{a_{1}}\left(x^{(1)}(1)-\frac{\sum_{i=2}^{p}\left(\frac{b_{i} c_{i}}{a_{i}}\right)+b}{a_{1}}\right) e^{-a_{1} k}+\frac{\sum_{i=2}^{p}\left(\frac{b_{i} c_{i}}{a_{i}}\right)+b}{a_{1}}
\end{aligned}
$$

From $\hat{x}_{1}^{(0)}(k)=\hat{x}_{1}^{(0)}(k)-\hat{x}_{1}^{(0)}(k-1),(k=2,3, \cdots, N)$, we got the simulated value of the original sequence $\left\{x_{1}^{(0)}(k)\right\}$; from $\hat{x}_{1}^{(0)}(k)=\hat{x}_{1}^{(0)}(k)-\hat{x}_{1}^{(0)}(k-1),(k=N+1, \cdots, N+q)$ we got the forecasted value of the original sequence $\left\{x_{1}^{(0)}(k)\right\}$ at the $q^{\text {th }}$ step.

\section{Empirical Analysis}

\subsection{Variables and Data}

Clean energy is energy which does not emit pollutants. It includes renewable energy, such as ocean energy, solar energy, wind energy, biological energy, hydraulic energy, geothermal energy, hydrogen energy, and so on, and nonrenewable energy, such as nuclear energy, and so on. Forecasting China's total consumption of clean energy has great significance for developing energy development strategies. Because the main influencing factors of clean energy consumption are economic scale and population size, and there are a total of three variables, this paper tries to simulate and forecast China's clean energy consumption using the grey model GM $(1,3)$. Because the conventional grey GM $(1, N)$ model has great simulation and forecasting errors, this paper improves the conventional model to obtain the improved grey model GM $(1, N)$, and then simulates and forecasts China's clean energy consumption 
with the improved grey model GM $(1, \mathrm{~N})$. the variables are selected as follows: $x_{1}^{(0)}(t)$ is the actual value of China's clean energy consumption (10,000 tons of standard coal); $x_{2}^{(0)}(t)$ is GDP (CNY 0.1 billion); $x_{3}^{(0)}(t)$ is the population (10,000 people). The time range is from 2006 to 2018 . The data source is the China Statistical Year Book, 2019, published by the National Bureau of Statistics of China. This paper uses software Matlab 2016a for calculation.

\subsection{Empirical Results}

Table 1 gives the related data of China's clean energy consumption from 2006 to 2018. This section builds an improved grey model GM $(1,3)$ for China's clean energy consumption.

Table 1. Related Data and Calculation Results of China's Clean Energy Consumption.

\begin{tabular}{|c|c|c|c|c|c|c|c|c|}
\hline \multirow{2}{*}{ Year } & \multirow{2}{*}{ No. } & \multirow{2}{*}{$\begin{array}{l}\text { Actual } \\
\text { Value } \\
x_{1}^{(0)}(t)\end{array}$} & \multirow{2}{*}{$\begin{array}{c}\text { Actual } \\
\text { Value } \\
x_{2}^{(0)}(t)\end{array}$} & \multirow{2}{*}{$\begin{array}{c}\text { Actual } \\
\text { Value } \\
x_{3}^{(0)}(t)\end{array}$} & \multicolumn{2}{|c|}{$\begin{array}{l}\text { Conventional Model } \\
\operatorname{GM}(1,3)\end{array}$} & \multicolumn{2}{|c|}{$\begin{array}{l}\text { Improved Model } \\
\text { GM }(1,3)\end{array}$} \\
\hline & & & & & $\begin{array}{l}\text { Simulated } \\
\text { Value }\end{array}$ & $\begin{array}{l}\text { Relative } \\
\text { Error \% }\end{array}$ & $\begin{array}{l}\text { Simulated } \\
\text { Value }\end{array}$ & $\begin{array}{c}\text { Relative } \\
\text { Error \% }\end{array}$ \\
\hline 2006 & 1 & $21,198.56$ & $219,438.5$ & $131,448.0$ & - & - & - & - \\
\hline 2007 & 2 & $23,358.15$ & $270,092.3$ & $132,129.0$ & $12,940.71$ & 44.60 & $23,923.56$ & 2.42 \\
\hline 2008 & 3 & $26,931.32$ & $319,244.6$ & $132,802.0$ & $24,140.84$ & 10.36 & $26,235.73$ & 2.58 \\
\hline 2009 & 4 & $28,570.71$ & $348,517.7$ & $133,450.0$ & $29,015.09$ & 1.56 & $28,820.47$ & 0.87 \\
\hline 2010 & 5 & $33,900.91$ & $412,119.3$ & $134,091.0$ & $31,980.87$ & 5.66 & $31,710.13$ & 6.46 \\
\hline 2011 & 6 & $32,511.61$ & $487,940.2$ & $134,735.0$ & $34,472.43$ & 6.03 & $34,940.91$ & 7.47 \\
\hline 2012 & 7 & $39,007.39$ & $538,580.0$ & $135,404.0$ & $36,965.61$ & 5.23 & $38,553.28$ & 1.16 \\
\hline 2013 & 8 & $42,525.13$ & $592,963.2$ & $136,072.0$ & $39,629.32$ & 6.81 & $42,592.51$ & 0.16 \\
\hline 2014 & 9 & $48,116.08$ & $641,280.6$ & $136,782.0$ & $42,535.38$ & 11.60 & $47,109.23$ & 2.09 \\
\hline \multirow[t]{2}{*}{2015} & 10 & $52,018.51$ & $685,992.9$ & $137,462.0$ & $45,726.16$ & 12.10 & $52,160.07$ & 0.27 \\
\hline & & & & & $\begin{array}{l}\text { Forecasted } \\
\text { Value }\end{array}$ & $\begin{array}{l}\text { Relative } \\
\text { Error \% }\end{array}$ & $\begin{array}{c}\text { Forecasted } \\
\text { Value }\end{array}$ & $\begin{array}{c}\text { Relative } \\
\text { Error \% }\end{array}$ \\
\hline 2016 & 11 & $57,988.00$ & $740,060.8$ & $138,271.0$ & $49,236.53$ & 15.09 & $57,808.36$ & 0.31 \\
\hline 2017 & 12 & $61,897.02$ & $820,754.3$ & $139,008.0$ & $53,101.13$ & 14.11 & $64,124.94$ & 3.60 \\
\hline 2018 & 13 & $66,352.00$ & $900,309.5$ & $139,538.0$ & $57,356.93$ & 13.56 & $71,189.00$ & 7.29 \\
\hline \multicolumn{5}{|c|}{ Average Simulation Relative Error (2006-2015) } & - & 11.55 & - & 2.62 \\
\hline \multicolumn{5}{|c|}{ Average Forecasting Relative Error (2016-2018) } & - & 14.29 & - & 3.73 \\
\hline \multicolumn{5}{|c|}{ Average Relative Error (2006-2018) } & - & 12.24 & - & 2.90 \\
\hline
\end{tabular}

First, build the GM $(1,1)$ model for GDP: $x_{2}^{(0)}(k)+a_{2} z_{2}^{(1)}(k)=c_{2}$.

To improve the simulation precision, we supposed the background value as $z_{2}^{(1)}(k)=\alpha x_{2}^{(1)}(k-1)+$ $(1-\alpha) x_{2}^{(1)}(k)$ and made $\alpha$ change from 0 to 1 by the step size of 0.01 , and then calculated the average simulation relative error $M A P E$. Figure 1 shows the results.

When $\alpha=0.41$, MAPE is the minimum and MAPE $=\frac{1}{N-1} \sum_{i=2}^{N}\left|\frac{x^{(0)}(t)-\hat{x}^{(0)}(t)}{x^{(0)}(t)}\right| \times 100 \%=4.62 \%$.

In this case, the background value is

$$
x^{(1)}\left(\xi_{k}\right)=0.41 x^{(1)}(k-1)+0.59 x^{(1)}(k)
$$

Then, we got the estimate of the parameter

$$
a_{2}=-0.097882, c_{2}=271521.0
$$


and then

$$
\begin{aligned}
x_{2}^{(1)}(t) & =\left(x_{2}^{(1)}(1)-\frac{c_{2}}{a_{2}}\right) e^{-a_{2}(t-1)}+\frac{c_{2}}{a_{2}} \\
& =2993401.0263 e^{0.097882(t-1)}-2773962.5263
\end{aligned}
$$

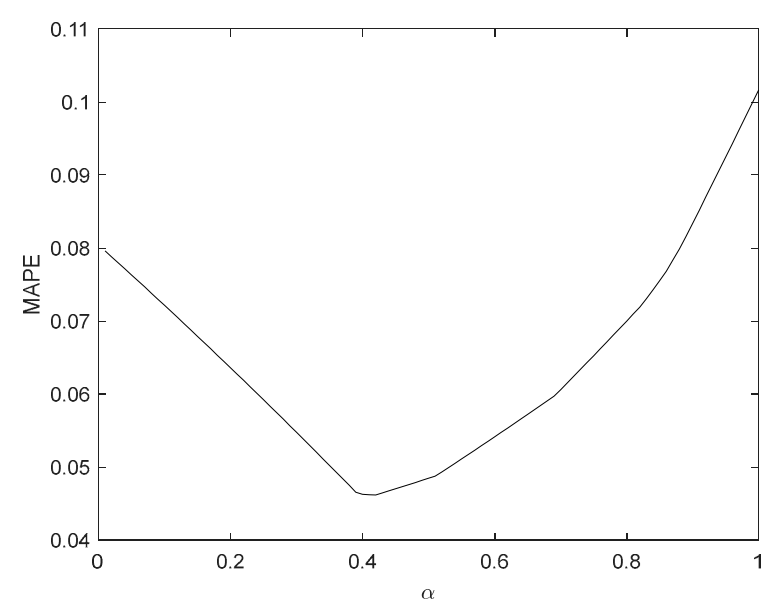

Figure 1. Curve of average simulation relative error changing with $\alpha$.

We then built the GM $(1,1)$ model for population size: $x_{3}^{(0)}(k)+a_{3} z_{3}^{(1)}(k)=c_{3}$.

To improve the simulation precision, we supposed the background value as $z_{2}^{(1)}(k)=\alpha x_{2}^{(1)}(k-1)+$ $(1-\alpha) x_{2}^{(1)}(k)$ and made $\alpha$ change from 0 to 1 by the step size of 0.01 , and then calculated the average simulation relative error MAPE. Figure 2 shows the results.

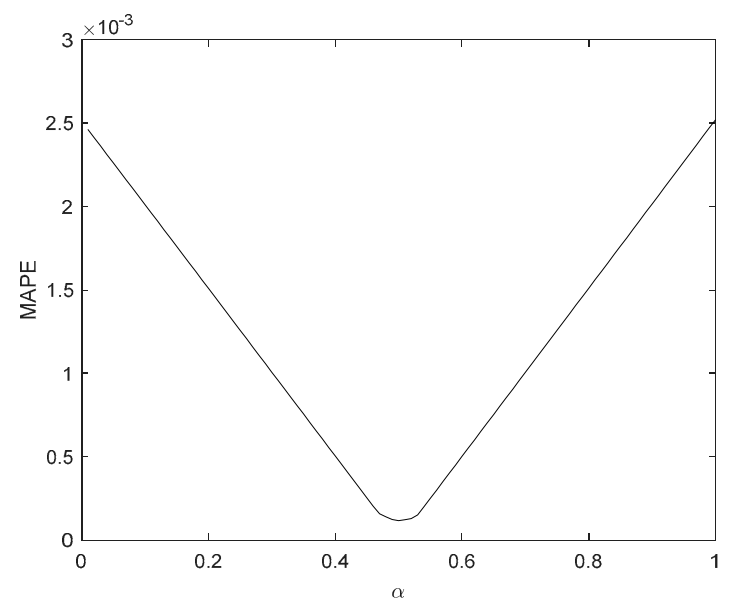

Figure 2. Curve of average simulation relative error changing with $\alpha$.

When $\alpha=0.50$, MAPE is the minimum and MAPE $=\frac{1}{N-1} \sum_{i=2}^{N}\left|\frac{x^{(0)}(t)-\hat{x}^{(0)}(t)}{x^{(0)}(t)}\right| \times 100 \%=0.0116 \%$.

In this case, the background value is

$$
x^{(1)}\left(\xi_{k}\right)=0.50 x^{(1)}(k-1)+0.50 x^{(1)}(k)
$$

Then, we got the estimate of the parameter

$$
a_{2}=-0.00492609, c_{2}=131156.0
$$


and then

$$
\begin{aligned}
x_{2}^{(1)}(t) & =\left(x_{2}^{(1)}(1)-\frac{c_{2}}{a_{2}}\right) e^{-a_{2}(t-1)}+\frac{c_{2}}{a_{2}} \\
& =26756215.3104 e^{0.004926(t-1)}-26624767.3104
\end{aligned}
$$

If we built the conventional GM $(1,3)$ model, i.e., the model was

$$
x_{1}^{(0)}(k)+a_{1} z_{1}^{(1)}(k)=b_{2} x_{2}^{(1)}(k)+b_{3} x_{3}^{(1)}(k)
$$

in which the background value $z_{1}^{(1)}(k)=0.5 x_{1}^{(1)}(k-1)+0.5 x_{1}^{(1)}(k)$.

From the grey differential equation, we got

$$
a_{1}=1.13401, b_{2}=0.0613443, b_{3}=0.100992
$$

The whitening equation is

$$
\frac{d x_{1}^{(1)}}{d t}+a_{1} x_{1}^{(1)}=b_{2} x_{2}^{(1)}+b_{3} x_{3}^{(1)}
$$

To get the analytical solution, we substituted the time response equation of GM $(1,1)$ for $x_{2}^{(1)}, x_{3}^{(1)}$ in the equation above, i.e.,

$$
\frac{d x_{1}^{(1)}(t)}{d t}+a_{1} x_{1}^{(1)}=\sum_{i=2}^{3} b_{i}\left[\left(x_{i}^{(1)}(1)-\frac{c_{i}}{a_{i}}\right) e^{-a_{i}(t-1)}+\frac{c_{i}}{a_{i}}\right]
$$

We got the solution

$$
\begin{aligned}
& x_{1}^{(1)}(t)=\sum_{i=2}^{3}\left[e^{a_{1}}\left(x^{(1)}(1)-\frac{b_{i} e^{a_{i}}\left(x_{i}^{(1)}(1)-\frac{c_{i}}{a_{i}}\right)}{a_{1}-a_{i}} e^{-a_{i}}\right) e^{-a_{1} t}+\frac{b_{i} e^{a_{i}}\left(x_{i}^{(1)}(1)-\frac{c_{i}}{a_{i}}\right)}{a_{1}-a_{i}} e^{-a_{i} t}\right] \\
& +e^{a_{1} t_{0}}\left(x^{(1)}(1)-\frac{\sum_{i=2}^{p}\left(\frac{b_{i} c_{i}}{a_{i}}\right)}{a_{1}}\right) e^{-a_{1} t}+\frac{\sum_{i=2}^{p}\left(\frac{b_{i} c_{i}}{a_{i}}\right)}{a_{1}}
\end{aligned}
$$

We substituted the related parameters, and then get the time response equation

$$
x_{1}^{(1)}(t)=64629.9241 e^{-1.13401 t}+135162.2760 e^{0.097882 t}+2360861.3890 e^{0.00492609 t}-2521176.6820
$$

We calculated the simulated value and the forecasted value of the original sequence from. See Table 1 for the results. Table 1 shows the relative errors and average relative errors in the periods.

Next, we built the improved grey model GM $(1,3)$ proposed.

The grey differential equation of improved grey model GM $(1,3)$ is

$$
x_{1}^{(0)}(k)+a_{1} z_{1}^{(1)}(k)=b_{2} z_{2}^{(1)}(k)+b_{3} z_{3}^{(1)}(k)+b
$$

The background value is $z_{i}^{(1)}(k)=\alpha x_{i}^{(1)}(k-1)+\alpha x_{i}^{(1)}(k),(i=1,2,3)$.

We let the generating coefficient $\alpha$ changes from 0 to 1 by the step size of 0.01 , calculated and got the average simulation relative error $M A P E$. Figure 3 shows the results.

When $\alpha=0.49$, MAPE is the minimum and MAPE $=\frac{1}{N-1} \sum_{i=2}^{N}\left|\frac{x^{(0)}(t)-\hat{x}^{(0)}(t)}{x^{(0)}(t)}\right| \times 100 \%=2.61 \%$.

In this case, the background value is

$$
z_{i}^{(1)}(k)=0.49 x_{i}^{(1)}(k-1)+0.51 x_{i}^{(1)}(k),(i=1,2,3)
$$


We calculated this and got

$$
a_{1}=-0.11054731, b_{2}=0.00014035613, b_{3}=-0.0038000549, b=20976.208
$$

The time response equation is

$$
\begin{aligned}
& x_{1}^{(1)}(t)=\sum_{i=2}^{3}\left[e^{a_{1}}\left(x^{(1)}(1)-\frac{b_{i} e^{a_{i}}\left(x_{i}^{(1)}(1)-\frac{c_{i}}{a_{i}}\right)}{a_{1}-a_{i}} e^{-a_{i}}\right) e^{-a_{1} t}+\frac{b_{i} e^{a_{i}}\left(x_{i}^{(1)}(1)-\frac{c_{i}}{a_{i}}\right)}{a_{1}-a_{i}} e^{-a_{i} t}\right] \\
& +e^{a_{1} t_{0}}\left(x^{(1)}(1)-\frac{\sum_{i=2}^{p}\left(\frac{b_{i} c_{i}}{a_{i}}\right)+b}{a_{1}}\right) e^{-a_{1} t}+\frac{\sum_{i=2}^{p}\left(\frac{b_{i} c_{i}}{a_{i}}\right)+b}{a_{1}}
\end{aligned}
$$

i.e.,

$$
x_{1}^{(1)}(t)=172965.5731 e^{0.11054737 T t}-30079.5140 e^{0.097882 t}+957908.4421 e^{0.00492609 t}-110145.9760
$$

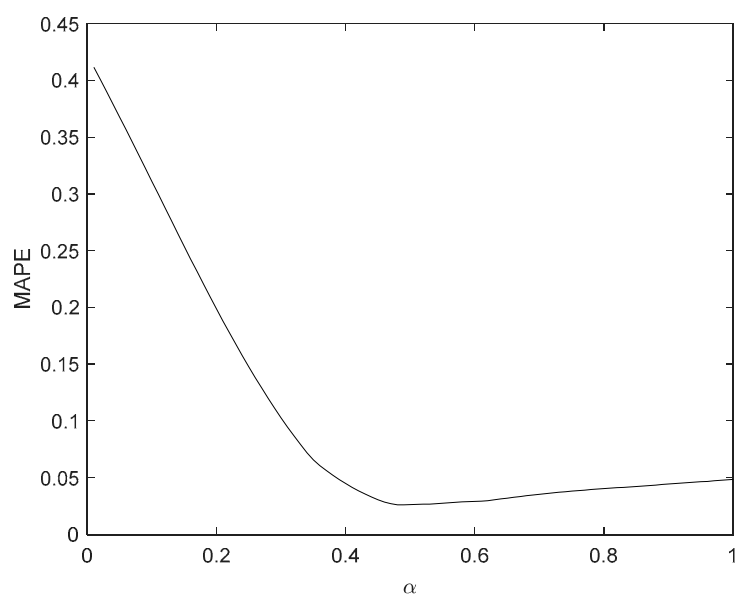

Figure 3. Curve of average simulation relative error changing with $\alpha$.

From $\hat{x}^{(0)}(t)=\hat{x}^{(1)}(t)-\hat{x}^{(1)}(t-1)$, we calculated the simulated value and forecasted value of original sequence. See Table 1 for the results. From the average simulation relative errors and the average forecasting relative errors, we can see that the improved model has the simulation and forecasting precision obviously superior to that of conventional models and shows an average simulation relative error of only $2.61103 \%$ and an average forecasting relative error of only $3.73303 \%$, far less than $10 \%$. The model has high precision and thus can be used for forecasting.

To compare the model proposed with other models in terms of simulation and forecasting precision, the paper builds the following three models using the data from year 2006 to year 2015.

The grey GM $(1,1)$ model built is

$$
\begin{gathered}
\hat{x}_{1}^{(1)}(t)=28872.9191 e^{0.093858(t-1)}-207674.3591 \\
R^{2}=0.9872
\end{gathered}
$$

From $\hat{x}_{1}^{(0)}(t)=\hat{x}_{1}^{(1)}(t)-\hat{x}_{1}^{(1)}(t-1),(t=2,3, \cdots, 10)$, get the simulated value of original sequence; from $\hat{x}_{1}^{(0)}(t)=\hat{x}_{1}^{(1)}(t)-\hat{x}_{1}^{(1)}(t-1),(t=11,12,13)$, get the forecasted value of original sequence at the third step. Table 2 shows the results.

The regression model built is

$$
\hat{x}_{1}^{(0)}(t)=-1010866.00-0.0346893 x_{2}^{(0)}(t)+7.89467 x_{3}^{(0)}(t)
$$




$$
R^{2}=0.9751
$$

From Equation (42), we calculated and got the simulated values, forecasted values and errors of $x_{1}^{(0)}(t)$ from the regression model. See Table 2 for the relevant results.

The difference equation model built is

$$
\begin{gathered}
\hat{x}_{1}^{(0)}(t)=349.74+0.30777 x_{1}^{(0)}(t-1)+0.87165 x_{1}^{(0)}(t-2) \\
R^{2}=0.9699
\end{gathered}
$$

From Equation (43), we calculated and got the simulated values, forecasted values and errors of

\begin{tabular}{|c|c|c|c|c|c|c|c|c|}
\hline \multirow{2}{*}{ Year } & \multirow{2}{*}{ No. } & \multirow{2}{*}{$\begin{array}{c}\text { Actual } \\
\text { Value } \\
x_{1}^{(0)}(t)\end{array}$} & \multicolumn{2}{|c|}{ Grey Model GM (1,1) } & \multicolumn{2}{|c|}{ Regression Model } & \multicolumn{2}{|c|}{$\begin{array}{c}\text { Difference Equation } \\
\text { Model }\end{array}$} \\
\hline & & & $\begin{array}{l}\text { Simulated } \\
\text { Value }\end{array}$ & $\begin{array}{l}\text { Relative } \\
\text { Error \% }\end{array}$ & $\begin{array}{l}\text { Simulated } \\
\text { Value }\end{array}$ & $\begin{array}{l}\text { Relative } \\
\text { Error \% }\end{array}$ & $\begin{array}{l}\text { Simulated } \\
\text { Value }\end{array}$ & $\begin{array}{l}\text { Relative } \\
\text { Error \% }\end{array}$ \\
\hline 2006 & 1 & $21,198.56$ & - & - & $19,266.83$ & 9.11 & - & - \\
\hline 2007 & 2 & $23,358.15$ & $22,521.97$ & 3.58 & $22,885.96$ & 2.02 & - & - \\
\hline 2008 & 3 & $26,931.32$ & $24,738.22$ & 8.14 & $26,494.01$ & 1.62 & $26,016.29$ & 3.40 \\
\hline 2009 & 4 & $28,570.71$ & $27,172.55$ & 4.89 & $30,594.29$ & 7.08 & $28,998.40$ & 1.50 \\
\hline 2010 & 5 & $33,900.91$ & $29,846.43$ & 11.96 & $33,448.48$ & 1.33 & $32,617.49$ & 3.79 \\
\hline 2011 & 6 & $32,511.61$ & $32,783.43$ & 0.84 & $35,902.47$ & 10.43 & $35,686.93$ & 9.77 \\
\hline 2012 & 7 & $39,007.39$ & $36,009.44$ & 7.69 & $39,427.35$ & 1.08 & $39,905.40$ & 2.30 \\
\hline 2013 & 8 & $42,525.13$ & $39,552.90$ & 6.99 & $42,814.47$ & 0.68 & $40,693.62$ & 4.31 \\
\hline 2014 & 9 & $48,116.08$ & $43,445.06$ & 9.71 & $46,743.59$ & 2.85 & $47,438.29$ & 1.41 \\
\hline \multirow[t]{2}{*}{2015} & 10 & $52,018.51$ & $47,720.21$ & 8.26 & $50,560.93$ & 2.80 & $52,225.24$ & 0.40 \\
\hline & & & $\begin{array}{l}\text { Forecasted } \\
\text { Value }\end{array}$ & $\begin{array}{l}\text { Relative } \\
\text { Error \% }\end{array}$ & $\begin{array}{l}\text { Forecasted } \\
\text { Value }\end{array}$ & $\begin{array}{l}\text { Relative } \\
\text { Error \% }\end{array}$ & $\begin{array}{l}\text { Forecasted } \\
\text { Value }\end{array}$ & $\begin{array}{l}\text { Relative } \\
\text { Error \% }\end{array}$ \\
\hline 2016 & 11 & $57,988.00$ & $52,416.06$ & 9.61 & $55,072.14$ & 5.03 & $58,299.61$ & 0.54 \\
\hline 2017 & 12 & $61,897.02$ & $57,574.00$ & 6.98 & $58,091.31$ & 6.15 & $63,538.37$ & 2.65 \\
\hline 2018 & 13 & $66,352.00$ & $63,239.49$ & 4.69 & $59,515.77$ & 10.30 & $69,944.73$ & 5.42 \\
\hline \multicolumn{3}{|c|}{$\begin{array}{l}\text { Average Simulation Relative } \\
\text { Error (2006-2015) }\end{array}$} & - & 6.90 & - & 3.90 & - & 3.36 \\
\hline \multicolumn{3}{|c|}{$\begin{array}{l}\text { Average Forecasting Relative } \\
\text { Error (2016-2018) }\end{array}$} & - & 7.09 & - & 7.16 & - & 2.87 \\
\hline \multicolumn{3}{|c|}{$\begin{array}{l}\text { Average Relative Error } \\
\text { (2006-2018) }\end{array}$} & - & 6.95 & - & 4.65 & - & 3.23 \\
\hline
\end{tabular}
$x_{1}^{(0)}(t)$ from the difference equation model. See Table 2 for the relevant results.

Table 2. Forecasting results of grey model GM $(1,1)$, regression model and difference equation model.

Tables 1 and 2 show that for China's clean energy consumption, the improved model GM $(1,3)$ has an average simulation relative error obviously smaller than those of the grey model GM $(1,1)$, regression model and difference equation model; the model proposed has an average forecasting relative error significantly smaller than those of the grey model GM $(1,1)$ and the regression model and slightly higher than that of the difference equation model. Overall, the improved model GM $(1,3)^{\prime} \mathrm{s}$ average relative error is significantly smaller than those of the grey model GM $(1,1)$, regression model and difference equation model. Therefore, the improved model GM $(1,3)$ built in this paper has the precision obviously superior to that of the grey model GM $(1,1)$, regression model and difference equation model. 
The results in Tables 1 and 2 show that the model built with the improved model proposed and the method proposed has high simulation precision and forecasting precision.

Table 3 shows the forecasted values of China's clean energy consumption from 2019 to 2025 obtained with the improved grey model GM $(1,3)$.

Table 3. Forecasted values of china's clean energy consumption.

\begin{tabular}{ccc}
\hline Year & No. & $\begin{array}{c}\text { Forecasted Value } \\
(\mathbf{1 0 , 0 0 0} \text { Tons of Standard Coal) }\end{array}$ \\
\hline 2019 & 14 & $79,089.1377$ \\
\hline 2020 & 15 & $87,924.4140$ \\
\hline 2021 & 16 & $97,805.6105$ \\
\hline 2022 & 17 & $108,856.6116$ \\
\hline 2023 & 18 & $121,215.9510$ \\
\hline 2024 & 19 & $135,038.5413$ \\
\hline 2025 & 20 & $150,497.6082$ \\
\hline
\end{tabular}

Figure 4 is the curve diagram of the actual value, simulated value and forecasted value of China's clean energy consumption. It shows that the improved grey model GM $(1,3)$ built in this paper has high fitting precision. The forecasting results in Table 3 show that by 2025, China's clean energy consumption shall reach 1.504976082 billion tons of standard coal. In this case, China's clean energy consumption shall increase by $11.32 \%$ annually on average from year 2019 to year 2025, far higher than the growth rate of the Chinese economy. It also indicates that China's economic growth shall have a great demand for clean energy in the future.

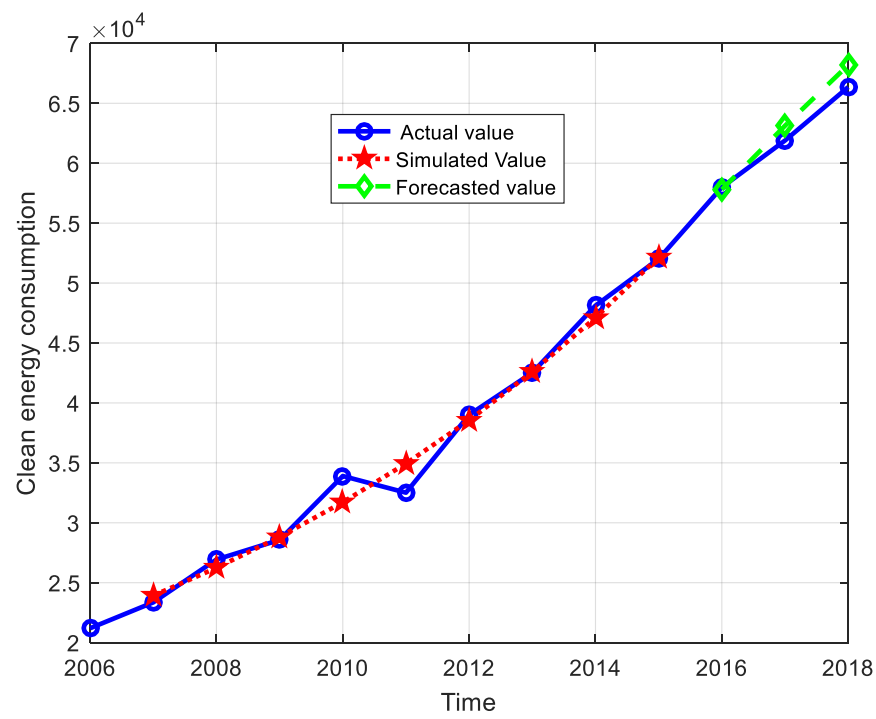

Figure 4. Curve Diagram of Actual Values, Simulated Value and Forecasted Values of China's Clean Energy Consumption.

\section{Conclusions and Discussion}

\subsection{Main Conclusions}

(1) This paper proposed an improved GM $(1, N)$ model and its modeling method for China's clean energy forecasting. To improve forecasting precision, the paper first derives the modified model of conventional grey differential equation based on the whitening equation, so that the grey differential 
equation obtained is structurally consistent with the whitening equation, and then substitutes the parameter estimate obtained from the grey differential equation into the solution of whitening equation (time response equation), in which case the forecasting error is small; next, the paper offers a parameter estimation method with optimized background value for the improved GM $(1, N)$ model; finally, to solve the problem that the time response equation of the conventional GM $(1, N)$ model generally has no analytical solution and is solved with the approximation method with a great forecasting error, the paper gives a scientific solving method for the time response equation of improved model.

(2) The paper builds the grey model GM $(1,3)$ for China's clean energy consumption using the improved model and method, and the model built has a simulation and forecasting precision significantly higher than that of conventional grey models. The improved model has a small average simulation relative error $(2.6110 \%)$ and a small average forecasting relative error $(3.7330 \%)$, indicating the method proposed is highly scientific and reliable. The idea and method in the paper also have great significance for further studies and wide applications of the grey GM $(1, N)$ model.

(3) For the purpose of comparison, the paper builds a grey model GM $(1,1)$, a regression model and a difference equation model for China's clean energy consumption. The comparison results show that the model built with the improved model has an average simulation relative error significantly smaller than those of grey GM $(1,1)$ model, regression model and difference equation model, and an average forecasting relative error significantly smaller than those of the grey model GM $(1,1)$ and regression model and slightly higher than that of difference equation model. Overall, the improved model GM $(1,3)$ built in this paper has an average relative error significantly smaller than those of grey model GM $(1,1)$, regression model and difference equation model. It indicates that the model built with the improved model and method proposed has high simulation and forecasting precision.

(4) The paper forecasts China's clean energy consumption from year 2019 to year 2025 using the improved grey model GM $(1,3)$. From the forecasting results, we can see that China's clean energy consumption from year 2019 to year 2025 is $0.7908913768,0.8792441395,0.9780561053,1.088566116$, $1.21215951,1.350385413$ and 1.504976082 billion tons of standard coal, respectively, increasing by $11.32 \%$ annually on average, far higher than China's economic growth rate. The Chinese government should further improve the energy supply system to avoid the lack of energy supply.

(5) From the macro perspective, China's consumption of clean energy, represented by nuclear power, wind power and solar energy, is closely connected to China's economic development and state policies. China's clean energy consumption shall grow rapidly with the growth of the economy and population, and accounting for a yearly increasing proportion in the total energy consumption. Currently, China is entering into a critical period of economic transition and update, energy pattern adjustment and overall social reform, so forecasting China's total consumption of clean energy is of great importance for Chinese government's energy development strategy adjustments and economic decisions in the future.

\subsection{Discussion}

Clean energy consumption has a great influence on economic growth, so forecasting China's clean energy consumption has important significance for China in making energy development strategies and sustainable economic development strategies. Because the main influencing factors of China's clean energy consumption are economic scale and population size and there are three variables in total, the paper tries to simulate and forecast China's clean energy consumption using the grey model $\operatorname{GM}(1,3)$. Because the conventional grey $\operatorname{GM}(1, \mathrm{~N})$ model has great simulation and forecasting errors, the paper improves the conventional model to obtain an improved GM $(1, N)$ model. The paper builds a grey GM $(1,3)$ model for China's clean energy consumption and gets the following calculation results: the average simulation error is $2.62 \%$, the average forecasting error is $3.73 \%$, the average overall error is $2.90 \%$; while, for the conventional model, the average simulation error is $11.55 \%$, the average forecasting error is $14.29 \%$ and the average overall error is $12.24 \%$. The results show that the improved 
grey model GM $(1, \mathrm{~N})$ built with the method proposed has greatly improved precision compared with the conventional model.

To compare the model built with other forecasting models, the paper builds a grey GM $(1,1)$ model, a regression model and a difference equation model. The calculation results show that the three model's average simulation errors are $6.90 \%, 3.90 \%$ and $3.36 \%$, respectively, the average forecasting errors are $7.09 \%, 7.16 \%$ and $2.87 \%$, respectively, and the average overall errors are $6.95 \%, 4.65 \%$ and $3.23 \%$, respectively. We can see that the improved grey GM $(1, N)$ model's simulation precision is significantly better than that of the grey GM $(1,1)$ model, regression model and difference equation model; meanwhile, the improved grey GM $(1, N)$ model's forecasting precision is significantly better than that of the GM $(1,1)$ model and regression model but not as good as that of the difference equation model. Overall, the improved grey model GM $(1,1)$ built with the method proposed has significantly better precision compared with other models here.

This paper forecasts China's clean energy consumption from 2019 to 2025 using an improved grey model GM $(1,3)$. Forecasting results show that China's clean energy consumption shall be 1.504976082 billion tons of standard coal by 2025. It indicates that China's clean energy consumption shall increase by $11.32 \%$ yearly on average from 2019 to 2025 , far exceeding the rate of economic growth. It also means China's economic growth has a great demand for clean energy in the future. The research shows that China's clean energy consumption demand shall increase rapidly with the growth of economy and population, so China should ensure the adequate supply of clean energy.

China's clean energy studied in the paper includes renewable energy, such as ocean energy, solar energy, wind energy, biological energy, hydraulic energy, geothermal energy, hydrogen energy, and so on, and nonrenewable energy, such as nuclear energy, and so on. Because the official statistics are about the gross consumption of all varieties of clean energy, and only part of the recent data are about different types of clean energy, we cannot forecast different types of energy respectively. As the statistics are perfected and improved, the research and forecasting of various types of energy consumption shall have greater significance.

Author Contributions: Data curation, Y.L.; Funding acquisition, M.C.; Methodology, M.C.; Software, J.L.; Validation, B.L.; Writing-original draft, M.C. All authors have read and agreed to the published version of the manuscript.

Funding: This research was funded by National Natural Science Foundation of China (No. 11401418).

Conflicts of Interest: The authors declare no conflict of interest.

\section{References}

1. Qian, Z.; Pei, Y.; Zareipour, H.; Chen, N. A review and discussion of decomposition-based hybrid models for wind energy forecasting applications. Appl. Energy 2019, 235, 939-953. [CrossRef]

2. Lu, S.L. Integrating heuristic time series with modified grey forecasting for renewable energy in Taiwan. Renew. Energy 2019, 133, 1436-1444. [CrossRef]

3. Tsai, S.B. Using grey models for forecasting China's growth trends in renewable energy consumption. Clean Technol. Environ. Policy 2016, 18, 563-571. [CrossRef]

4. Abedinia, O.; Amjady, N.; Ghadimi, N. Solar energy forecasting based on hybrid neural network and improved metaheuristic algorithm. Comput. Intell. 2018, 34, 241-260. [CrossRef]

5. Reikard, G.; Robertson, B.; Buckham, B.; Bidlot, J.R.; Hiles, C. Simulating and forecasting ocean wave energy in western Canada. Ocean Eng. 2015, 103, 223-236. [CrossRef]

6. Yang, W.D.; Wang, J.Z.; Lu, H.Y.; Niu, T.; Du, P. Hybrid wind energy forecasting and analysis system based on divide and conquer scheme: A case study in China. J. Clean. Prod. 2019, 222, 942-959. [CrossRef]

7. Xiao, L.; Wang, J.Z.; Dong, Y.; Wu, J. Combined forecasting models for wind energy forecasting: A case study in China. Renew. Sustain. Energy Rev. 2015, 44, 271-288. [CrossRef]

8. Rodriguez, F.; Fleetwood, A.; Galarza, A.; Fontan, L. Predicting solar energy generation through artificial neural networks using weather forecasts for microgrid control. Renew. Energy 2018, 126, 855-864. [CrossRef] 
9. Kim, D.; Hur, J. Short-term probabilistic forecasting of wind energy resources using the enhanced ensemble method. Energy 2018, 157, 211-226. [CrossRef]

10. Zheng, C.W.; Li, C.Y.; Chen, X.; Pan, J. Numerical Forecasting Experiment of the Wave Energy Resource in the China Sea. Adv. Meteorol. 2016, 2016, 5692431. [CrossRef]

11. Reikard, G.; Robertson, B.; Bidlot, J.-R. Combining wave energy with wind and solar: Short-term forecasting. Renew. Energy 2015, 81, 442-456. [CrossRef]

12. Galván, I.M.; Valls, J.M.; Cervantes, A.; Aler, R. Multi-objective evolutionary optimization of prediction intervals for solar energy forecasting with neural networks. Inf. Sci. 2017, 418-419, 363-382. [CrossRef]

13. Li, Y.; Wen, Z.; Cao, Y.J.; Tan, Y.; Sidorov, D.; Panasetsky, D. A combined forecasting approach with model self-adjustment for renewable generations and energy loads in smart community. Energy 2017, 129, $216-227$. [CrossRef]

14. Li, Z.X.; Rahman, S.M.M.; Vega, R.; Dong, B. A Hierarchical Approach Using Machine Learning Methods in Solar Photovoltaic Energy Production Forecasting. Energies 2016, 9, 55. [CrossRef]

15. Jeon, J.; Taylor, J.W. Short-term density forecasting of wave energy using ARMA-GARCH models and kernel density estimation. Int. J. Forecast. 2016, 32, 991-1004. [CrossRef]

16. Ibarra-Berastegi, G.; Saenz, J.; Esnaola, G.; Ezcurra, A.; Ulazia, A. Short-term forecasting of the wave energy flux: Analogues, random forests, and physics-based models. Ocean Eng. 2015, 104, 530-539. [CrossRef]

17. Merigaud, A.; Ramos, V.; Paparella, F.; Ringwood, J.V. Ocean forecasting for wave energy production. J. Mar. Res. 2017, 75, 459-505. [CrossRef]

18. Ma, J.; Oppong, A.; Acheampong, K.N.; Abruquah, L.A. Forecasting Renewable Energy Consumption under Zero Assumptions. Sustainability 2018, 10, 576. [CrossRef]

19. Martín-Vázquez, R.; Aler, R.; Galván, I.M. Wind Energy Forecasting at Different Time Horizons with Individual and Global Models. Artif. Intell. Appl. Innov. 2018, 519, 240-248.

20. Mehedintu, A.; Sterpu, M.; Soava, G. Estimation and Forecasts for the Share of Renewable Energy Consumption in Final Energy Consumption by 2020 in the European Union. Sustainability 2018, 10, 1515. [CrossRef]

21. Dumitru, C.-D.; Gligor, A. Wind Energy Forecasting: A Comparative Study Between a Stochastic Model (ARIMA) and a Model Based on Neural Network (FFANN). Procedia Manuf. 2019, 32, 410-417. [CrossRef]

22. Li, Q.F.; Dang, Y.G.; Wang, Z.X. Analysis of the regional coordination development systems based on GRA and GM (1, N). J. Grey Syst. 2012, 24, 95-100.

23. Deng, C.Y.; Zhang, S.T. Numerical mapping in DNA sequences and analysis of the genetic information by GM (1, N). J. Grey Syst. 2012, 24, 217-224.

24. Ren, J.Z.; Gao, S.Z.; Tan, S.Y.; Dong, L.C. Prediction of the yield of biohydrogen under scanty data conditions based on GM (1, N). Int. J. Hydrog. Energy 2013, 38, 13198-13203. [CrossRef]

25. Pai, T.Y.; Chiou, R.J.; Wen, H.H. Evaluating impact level of different factors in environmental impact assessment for incinerator plants using GM $(1, \mathrm{~N})$ model. Waste Manag. 2008, 28, 1915-1922. [CrossRef]

26. Wang, H.L. Modeling and simulation of regional energy consumption prediction of Henan province considering urban expansion based on inverse GM (1, N) in China. J. Appl. Sci. 2013, 13, 4327-4331. [CrossRef]

27. Wang, Z.X. Multivariable time-delayed GM (1, N) model and its application. Control Decis. 2015, 30, $2298-2304$.

28. Su, H.J.; Shao, Y. On Approximating Grey Model GM (1, N). Sichuan Univ. Arts Sci. J. 2013, 23, 7-10.

29. Huang, J. Grey GM (1,N|T,r) model and its particle swarm optimization algorithm. Syst. Eng. Theory Pract. 2009, 29, 145-151.

30. Zhang, G.F.; Jiang, G.H.; Fu, Y.F.; Shen, B.; Huang, L.M. Establishment of the grey GM (1, N) self-memory model. J. Shenyang Agric. Univ. 2009, 40, 210-214.

31. He, M.X.; Wang, Q. New algorithm for GM $(1, N)$ modeling based on Simpson formula. Syst. Eng. Theory Pract. 2013, 33, 199-202.

32. Ding, S.; Dang, Y.G.; Xu, H. Construction and application of GM $(1, N)$ based on control of dummy variables. Control Decis. 2018, 33, 309-315.

33. Zhou, W.; Fang, Z.G. Nonlinear optimization method of gray GM $(1, \mathrm{~N})$ model and Application. Syst. Eng. Electron. 2010, 32, 317-320.

34. Wang, Q.P.; Yan, H.X.; Yan, J.B. The application of grey GM (1, N) model with the Markov residual error correction to grain yield forecasting. J. Xian Univ. Technol. 2009, 25, 347-350. 
35. Bi, X.J.; Wu, X.A. Study of a multistage grey model GM $(1, \mathrm{~N})$ with feedback Mechanisms. J. Harbin Eng. Univ. 2007, 28, 577-580.

36. Zeng, B.; Luo, C.M.; Liu, S.F.; Bai, Y.; Li, C. Development of an optimization method for the GM (1, N) model. Eng. Appl. Artif. Intel. 2016, 55, 353-362. [CrossRef]

37. Huang, Q.F.; Wei, Y. GM (1, N) Model Multi-variable Forecast. J. Grey Syst. 2016, 22, 319-324.

38. Tien, T.L. A research on the grey prediction model GM (1, N). Appl. Math. Comput. 2012, 218, $4903-4916$. [CrossRef]

39. Wang, Y.H.; Liu, Q.; Tang, J.R.; Cao, W.B.; Li, X.Z. Optimization approach of background value and initial item for improving prediction precision of GM $(1,1)$ model. Syst. Eng. Electron. 2014, 25, 77-82. [CrossRef]

40. Wang, Z.X.; Dang, Y.G.; Liu, S.F. Optimization of background value in GM $(1,1)$ model. Syst. Eng. Theory Pract. 2008, 28, 61-67. [CrossRef]

41. Madhi, M.H.; Mohamed, N. An improved GM $(1,1)$ Model based on modified background value. Inform. Technol. J. 2017, 16, 11-16. [CrossRef]

42. Pei, L.L.; Chen, W.M.; Bai, J.H.; Wang, Z.X. The improved GM (1, N) models with optimal background values: A case study of Chinese high-tech industry. J. Grey Syst. 2015, 27, 223-233.

43. Wang, Z.X.; Dang, Y.G.; Liu, S.F. The optimization of background value in GM $(1,1)$ model. J. Grey Syst. 2007, 10, 69-74. [CrossRef]

44. Xie, N.M.; Yin, S.M.; Hu, C.Z. Estimating a civil aircraft's development cost with a GM (1, N) model and an MLP neural network. Grey Syst. Theory Appl. 2017, 7, 2-18. [CrossRef]

45. Liu, Z.Q.; Zhang, J.L.; Liao, J.Q. The analysis of key influence factors on turnover intention of staff based on GM (1, N). J. Grey Syst. 2005, 17, 133-140.

46. Pan, X.G.; Li, X.F.; Chen, M.L.; Wang, S.Q. Prediction of FCU characteristics based on GM (1, N) model. Sci. Technol. Rev. 2013, 31, 66-70.

47. Chang, K.Y.; Teng, Y.W.; Chen, T.R. Study of power estimation and competitive electrical power management in LEV based on Gray model GM (1, N). Int. J. Green Energy 2016, 13, 1254-1266. [CrossRef]

48. Ren, J.Z. GM $(1, N)$ method for the prediction of anaerobic digestion system and sensitivity analysis of influential factors. Bioresour. Technol. 2018, 247, 1258-1261. [CrossRef] 